\title{
The effects of hypoxia on shuttle avoidance in the rat
}

FRANK LEOWITH

DEPARTMENT OF PSYCHOLOGY, UNIVERSITY OF ADELAIDE

Four groups of six rats each were tested on the acquisition of shuttle avoidance at one of four levels of oxygen concentration between $21 \%$ (normal air) and $9 \%$. Initially performance was poorer at $9 \%$ though with repeated testing the differences between the groups diminished. Subsequent testing of all groups at $9 \% \mathrm{O}_{2}$ gave evidence that the reduction in the effect of oxygen deprivation could be attributed in part to physiological adaptation i.e. acclimatization.

Animal studies reports have been published on the effects of hypoxia (reduced oxygen in the inspired air) given before (Hurder, 1951) and after (Thomson, 1957) learning trials. However, there is little previous evidence on the effects observed when hypoxia is induced during learning. Weinstein (1966), however, reports on the effects of hypoxia on $\mathrm{CO}_{2}$ escape in mice: Severe hypoxia (6\% $\mathrm{O}_{2}$ or less) increases the time taken to escape, though mild hypoxia $\left(10 \% \mathrm{O}_{2}\right)$ is associated with quicker times than normal air $(21 \%$ $\mathrm{O}_{2}$ ). This paradoxical effect may be unique to the particular noxious stimulus used, but is not necessarily so.

It has been repeatedly suggested that hypoxda affects the learning of a response more than its performance once leamed (e.g., Denison, Ledwith, \& Poulton, 1966). Hence the present experiment on rats is a study of the effects of hypoxia on the acquisition of shuttle avoidance: Learning would be expected to be complete in 50 trials, and the whole course of acquisition can be studied (Mowrer \& Lamoreaux, 1942).

Method

The apparatus used was a box 36 in. $x 6$ in. with 18 in. high sides. It was divided into 2 in. $\times 18$ in. long compartments by a partition having a 2 in. gap at the base. The grid floor was connected by way of a four relay shock scrambler to a power source giving $0.2 \mathrm{~mA}$ shock. This shock could be switched to each compartment separately. The interior of the box was painted white, and high on each end wall a $10 \mathrm{~W}$ lamp was mounted.

The box was enclosed in a sealable plastic bag, which also contained six mesh retaining cages $(5 x$ $5 \times 5$ in.), in which animals awaited their turns in the shuttle box. Varying mixtures of $\mathrm{O}_{2}$ and $\mathrm{N}_{2}$ were fed in to vary the $\mathrm{O}_{2}$ concentration, which was monitored by a Beckman Oxygen Analyzer.

Ss were 12 hooded and 12 albino male rats, aged 3 months and supplied by the University animal house. They were housed two to a cage in the laboratory for one month prior to the start of the experiment, and during this time were handled occasionally. They were pre-trained to a criterion of eight successive escapes within $10 \mathrm{sec}$ from the shock presented without prior warning. Four groups of rats were made up, matched on the basis of spontaneous activity in the experimental box in the $5 \mathrm{~min}$ adaptation period prior to the first shock of escape training.

Each group was repeatedly exposed to one $\mathrm{O}_{2}$ concentration: $21 \%$ (normal air), $17 \%, 13 \%$, or $9 \%$. Testing was carried out in five separate sessions, run twice weekly for each group with three or four days between each session. After this, all groups were tested once at $9 \% \mathrm{O}_{2}$.

The same testing procedure was used in each session. All six animals in a group were placed in the retaining cages. The bag was closed, and $\mathrm{N}_{2}$ fed in at a rate of 6 liters per $\mathrm{min}$ for $30 \mathrm{~min}$. Once the desired $\mathrm{O}_{2}$ concentration was attained within this period, $\mathrm{O}_{2}$ was added to maintain a steady level. After this period the flow rate was dropped to 3 liters per min and maintained at that for the rest of the session. Fifteen min after the gas flow was reduced, the first rat was placed in the shuttle box and allowed to rest there for $5 \mathrm{~min}$. The warning light was then turned on in the compartment in which the animal was sitting. Ten sec later the shock was turned on for a further 10 sec unless the animal escaped to the other compartment, which had no shock. The warning light was turned off as soon as the rat left the lighted compartment in escape or in avoidance (before the onset of the shock). An intertrial interval of $90 \mathrm{sec}$ was allowed, and each $\mathrm{S}$ was given 10 trials per day. The whole testing session for six rats lasted $3 \mathrm{~h}$. Time taken to avoid or escape the shock was recorded on a hand held stop watch.

Results and Discussion

On the first day of testing the mean number of avoidance responses (Fig. 1) was markedly poorer in the $9 \% \mathrm{O}_{2}$ group than in the other three groups. By Day 5 this difference was much reduced. This reduction could be (a) a ceiling effect, since no animal can score more than 10 avoldances per day, or (b) an example of the reduction in the effects of hypoxia with practice at the task.

When all groups were subsequently tested at $9 \% \mathrm{O}_{2}$, animals which had previously been hypoxic were better than the control animals (Fig. 2). How much better was directly related to the severity of prior oxygen deprivation.

This suggests that the improvement in performance 


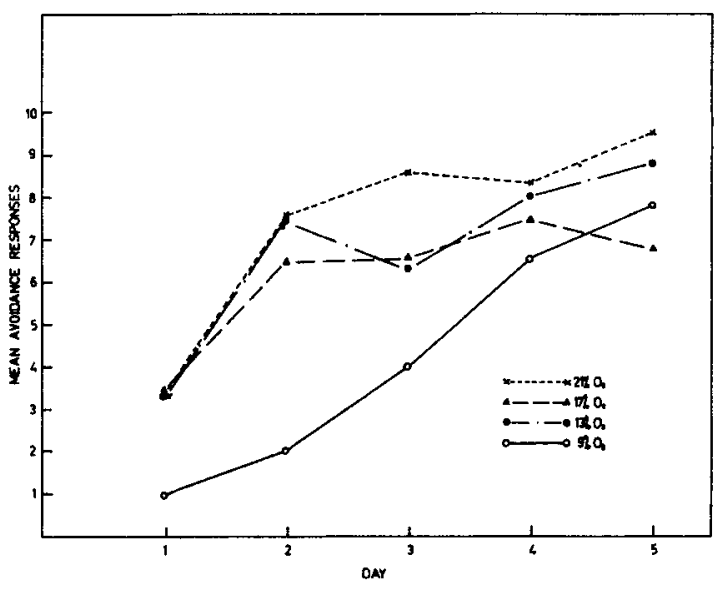

Fig. 1. Mean number of avoidance responses for each group of six rats at four levels of $\mathrm{O}_{2}$ on five days of testing.

of the low $\mathrm{O}_{2}$ groups was, in part at least, a result of physiological adaptation (acclimatization). Had the improvement been from psychological effects alone, the $21 \% \mathrm{O}_{2}$ group would have been at least as good as the other three groups and not the worst.

The median times to avoid and escape the shock were not markedly different in the four groups and show no systematic relationship to $\mathrm{O}_{2}$ level. If there were any effects similar to those described by Weinstein (1966), they were too small to be detected by the crude timing used or are not found with the particular $\mathrm{O}_{2}$ concentrations used.

The suggestion of physiological acclimatization is unexpected. Van Liere \& Stickney (1963) suggest that In rats even daily exposure to hypoxia for several hours fails to show unequivocal evidence of acclimatization. The pattern in this experiment of $3 \mathrm{~h}$ once every three or four days was dictated by the experimental design used; there appear to be no relevant physiological studies of such a routine. If this supposed acclimatization effect is generally substantiated, studies involving repeated testing of animals in hy-



Fig. 2. Mean avoidances of each group of $\operatorname{six}$ rats at $9 \% \mathrm{O}_{2}$ as a function of $\mathrm{O}_{2}$ cuncentration experienced in previous five days of testing.

poxia will have to be designed with this in mind. It is possible that this effect is a partial explanation for the failure of previous studies (Seitz \& Keller, 1940; Shock \& Scow, 1942) to show any marked effects of hypoxia on learning in rats.

\section{References}

Denison, D. M., Ledwith, F., \& Poulton, E. C. Complex reaction times at simulated cabin altitudes of $5,000 \mathrm{ft}$. and $8,000 \mathrm{ft}$. Aerospace Medicine, 1966, 37, 1010-1013.

Hurder, $W . P$. Changes in maze performance in rats following exposure to anoxia. J. comp. physiol. Psychol., 1951, 44, 473-478.

Mowrer, O. H., \& Lamoreaux, R. R. Avoidance conditioning and signal duration. Psychol. Monogr., 1942, 54, 5, Whole No. 247.

Seitz, C. P., \& Keller, F. S. Oxygen deprivation and conditioning in the white rat. J. Aviat. Med., 1940, 11, 210-213.

Shock, N. W., \& Scow, R. O. The effect on learning of repeated exposure to lowered oxygen tension in the inspired air. J. comp. physiol. Psychol., 1942, 34, 55-63.

Thompson, R. The comparative effects of E.C.S. and anoxia on memory. J. comp. physiol. Psychol., 1957, 50, 397-400.

Van Liere, E. J., \& Stickney, J. C. Hypoxia. University of Chicago Press, 1963.

Weinstein, S. A. The effect of hypoxia on learned escape from carbon dioxide. Psychon. Sci., 1966, 6, 91-92. 